\title{
I Can haz Stail: a Language Style of LOLcat Meme in icanhas.cheezburger.com
}

\author{
Daniel P. Laksono \& Adventina Putranti \\ English Letters Department, Sanata Dharma University, Yogyakarta \\ danielaksono@gmail.com \& putranti@usd.ac.id
}

\begin{abstract}
The viral phenomenon of LOLcat meme makes many researchers study this internet meme. Although its words and sentences are unconventional, people can apply this unconventional English so that the meme became viral. It is even used in other forms of meme such as Bible, books, and a musical theater. The fact that the English is unconventional but makes the meme viral is what inspires this study. Henceforth, this study aims to find reasons how such unconventional English syntax strengthen the virality of LOLcat meme.
\end{abstract}

Key words: internet meme, viral phenomenon, unconventional English

\section{Introduction}

Internet has changed how human interacts with each other. In term of communication, most human use an internet to send messages directly and rapidly. Nowadays, people are familiar with communication applications such as WhatsApp, BBM, Facebook Messenger, or LINE. Those applications use an internet connection to send messages in form of texts, voices, and pictures. These methods are famous because internet communications combine the speed and writing as it is called a "written speech" (Crystal, 2001: 25). Each message is written and read so often as it is being spoken.

While those examples of communication method provide speed and writing, internet memes does not provide so. They usually have unconventional English in their writings to express idea. In this paper, the writer analyzes LoLcat meme uploaded in icanhas.cheezburger.com. This kind of meme is chosen because their appearance in that website is meant as a communication tool. When this meme is uploaded, other users will give comments about it. Although many words are unconventional, LOLcat meme is one of the famous memes in the internet world.

To achieve the goal of this research, the writer sums up into these following two questions:

1. What are the differences between the English used in LOLcat meme and the conventional English?

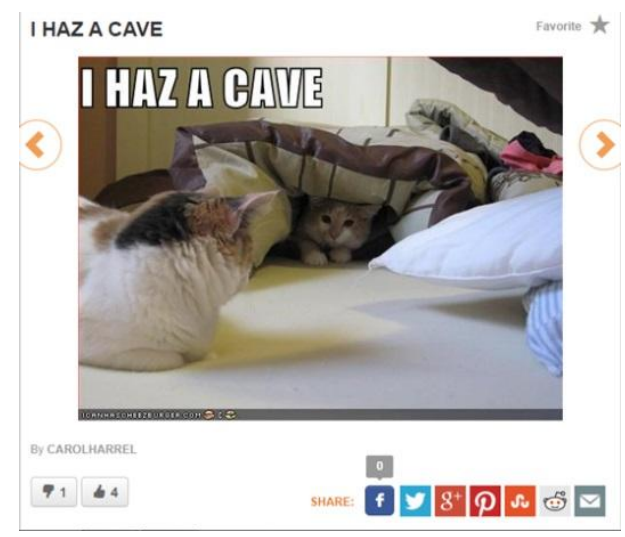

While the sentence in the picture above is $I$ haz a cave, the readers' inner ear will be I has a cave. To understand how the sentences differ from conventional English, the writer uses a theory of syntax. However, as seen 
there that the unconventional form also occurs in its words, the writer uses a theory of morphology whenever it is necessary. The analysis result of morphology is very important to know how a LOLcat words is formed in English. The purpose of morphological analysis is explaining that the LOLcat word $h a z$ is similar to an English word has. When it is proven that haz is actually an English verb has, the writer can reveal the unconventional English syntax in LOLcat meme.

\section{What is the effect of unconventional English syntax toward the virality of LOLcat meme?}

Most words and sentences in LOLcat meme are unconventional. However, this meme is famous since it inspires people to create a website (icanhas.cheezburger.com), a book (Eric Nakagawa in "I Can Has Cheezburger?: A LOLcat Colleckshun), a musical theater (Kristyn Pomranz and Katherine Steinberg, I Can Has Cheezburger: The MusicLOL!); a musical theater was a part of FringeNYC 2009), and a translation of The Holy Bible (a work done by Martin Grondin and can be accessed in lolcatbible.com). The curiosity comes up on how such unconventional English affects the virality of LOLcat meme.

Those questions are answered using a stylistic theory with any other additional ones. As the writer experienced while doing this research, some words need to be analyzed using theories which are not included in the framework. It indicates that creativity in LOLcat-meme world goes beyond our present linguistic theories.

\section{Meme and the Internet}

Meme is introduced by Richard Dawkins in 1976 to explain about cultural spreading, human behavior, and development in the society (Buchel, 2012: 7). Meme means imitation of ideas that spread among human brains. Examples of meme are concept, tune, fashion which propagate through advertisement, social media, news, or communication.
Not all memes or ideas can propagate widely. As a human cannot remember all ideas that he got in a day, only strong memes can survive. The need of a meme is not how good the meme is but how the core idea of it can catch its receiver's attention (Blackmore, 1999: 57). Dawkins argue that there are three characteristics which make a meme can survive: fidelity, fecundity, and longevity.

Fidelity refers to how strong the idea of the meme is. The stronger it is, the more successful it becomes. In other words, fidelity is an ability of a meme to be memorized. In terms of language, fidelity is maintained by digitalizing the sound. The propagation of a meme will have a high fidelity if it is digital.

While fidelity refers on how the meme can be memorized, fecundity refers to the rate of a meme is being copied (Ritt, 2004: 123). If a meme $A$ is copied five times per minute while a meme $B$ is copied ten times per minute, the chance for meme $B$ to get people's attention is bigger. It occurs in a language since it strengthens the propagation of memes. Through language, memes can propagate in a longer distance and to more brains. Imagine a person who wants to spread a meme "she runs away!". With a shouting in a language, people can hear the meme, react toward it even in the dark.

The third characteristic of a strong meme is longevity which refers on how long the idea can stay longer in the memory. The longer it is, the more it is possible to spread. Language here exists to help people memorize the meme, as it is troublesome to remember dance steps but remembering "slow, quick, slow, slow" is much easier. Using sentences rather than any meaningless noises, people are easy to repeat stories or sentences.

That rapid growth of meme becomes much stronger in internet. While speech language provides fidelity and fecundity but can be problematic in longevity, writing system and internet maintain the need of longevity. When a meme is made and saved in a computer, the meme or the idea stays there. If the user uploads it in the internet, anyone can see and copy it as it is. In here, the meme propagates in limitless brain and space. The 
meme may stay in a computer in Singapore but people from Brazil can see it through internet.

However, today internet users have a term which is called internet meme. Although it is slightly different from original meme since it only indicates humorous situation, the internet meme also provides ideas which is spread using internet as its media. According to Bc. Branislav Buchel, a meme is rapidly spread by means of electronic communication such as e-mail, forums, image boards or chat. They are formed into media objects such as video, pictures, text, or audio recording.

\section{LOLcat as an Internet Meme}

In 2005, an internet meme called LOLcat is first appeared in a website called 4chan.com. In this study, the writer analyzes LOLcat meme appeared in icanhas.cheezburger.com. Realizing that users can write anything anonymously and even create other language variations, this study aims to say that such variations exists while at the same time they strengthen the virality of LOLcat meme.

LOLcat meme can easily be identified since it always has a picture of cat in it. The cat varies in positions or gestures and amounts. LOLcat meme itself is not the only meme exists in the internet. Knowyourmeme.com counts that there are around 2.116 kinds of internet meme in the internet (www.knowyourmeme.com/ memes: May 10, 2015). Those numbers are still counting as more people could create other memes.

Surprisingly, LOLcat meme is the only meme that has its own website. It is icanhas.cheezburger.com which is built as a dedication of LOLcat meme. In this website, users from all around the world share humorous ideas about LOLcat meme every day. According to statstool.com, the website has around 48.000 visitors and 439.800 page views each day (cheezburger.com.statstool.com/:23 June 2015).

\section{I can haz cheezburger?: the LOLcat Language}

Although the language appears in a written form, analyzing LOLcat language is quite challenging. In aiming to analyze the language using stylistics, the writer started the analysis from morphological and syntactic analysis. The language in LOLcat always derives from conventional English which then transformed into something on how the cat would talk (Dash, www.dashes.com/anil/2007/04/cats-canhas-gr.html, 23 April 2007). Based on the result of study, LOLcat language is not only how the message is written but also how it sounds. The writer uses 8 LOLcat memes in the website to show that such a phenomenon occurs in the internet world.

\section{Picture 1}

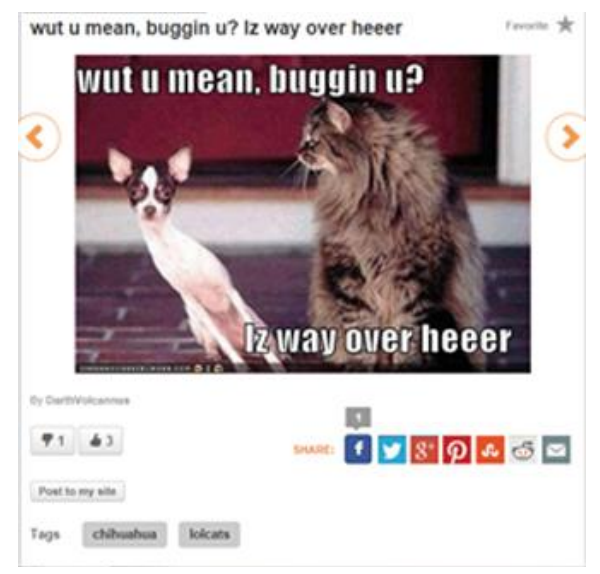

Picture 1 consists of 2 sentences: the first which written wut $u$ mean, buggin $u$ ? and the second sentence which written Iz way over heeer.

In this meme, the writer finds something new on how the unconventional words written here are made. For the first sentence, it has a nonstandard spelling feature. In this nonstandard spelling, users implement the pronunciation; the words written in this meme are created as any influences of pronunciation. In here, when a reader reads wut $u$ mean buggin $u$ ? his inner ear produces "what you mean bugging you?". There, a wut word is derived from conventional English word "what". "What" in English is pronounced /wbt/, /wa:t/, or /wst/. For the vowel in "what", it has a similar sound with a 
word like "cut" /kıt/. In simple words, letter $\mathrm{u}$ sometimes is pronounced $/ \Lambda /$. The user then rewrites the letter $u$ because it shares the same vowel. Consequently, -ha- in "what" is replaced, which is finally forms into wut.

Besides nonstandard spelling, the first sentence also applies logogram to replace "you" with a letter "u" since both of them have the same pronunciation /ju:/. Moreover, a clipping feature also occurs by deleting $g$ in conventional English word "bugging" which becomes buggin.

As seen above, according to the morphological analysis, the conventional English version of the first sentence is what you mean, bugging you? In English, this sentence is called a verb clause where one sentence describes another sentence in a same utterance. "Mean" is a transitive verb which needs two arguments. "You" as an experiencer, becomes the first argument, while "bugging you?" is a clause which becomes the second argument and also the theme of the sentence. However, the word "bugging" itself is a transitive verb which needs two arguments. Hence, the agent of "bugging" is missing. By looking at the second sentence and the picture, the writer can determine what the word is. At the second sentence, the subject is "I". Hence, the subject for the word "bugging" in the meme is "I", not "we" or "she" or another pronoun.

Therefore, according to the analysis, the writer concludes that the conventional English sentence is "what do you mean I'm bugging you?" and "what do you mean? Am I bugging you?". This conclusion comes up because in the sentence, there are two verbs: "mean and "bugging".

Henceforth, as an interrogative whquestion, the auxiliary verbs ("do" and "am") and the subject of the second clause ("I") are omitted. The modification makes the sentence only consists of verbs ("mean" and buggin) and its arguments.

For the second sentence, there is an $I z$ word which does not exist in English. With a capital letter of $i$ in $I z$, the writer finds that it refers to the conventional English word " $I$ ". while reading the word, reader's inner ear will hear $/ \Lambda \mathrm{Iz} /$ which is quite similar when people utter I'm $/ \Lambda \mathrm{Im} /$. Therefore, letter $z$ in the sentence is an abbreviation of an auxiliary verb.

In defining what $z$ refers to, the writer uses data from datum picture 3 . Picture 3 shows that LOLcat meme has an auxiliary verb $i z$. This auxiliary verb is what then, in picture 1, be attached with "I". Similar to English "I am" which is abbreviated into "I'm", the words $I$ iz is abbreviated into $I z$. When a reader reads the word $i z$, it creates a similar voice with a conventional English auxiliary verb "is". In English, "is" is pronounced /rz/. In here, the writer concludes that $i z$ is a nonstandard spelling using pronunciation implementation of an English auxiliary verb "is". Instead of using "is", users rewrite that pronunciation $(/ \mathrm{rz} /)$ so that $i z$ is written in the meme instead of "is".

The word heeer is written by repeating the letter $e$ to express feelings. It is applied to maintain the need of writing as talking (Crystal, 2001: 34-35). While letter $e$ is repeated, it means a long voice in speaking. Writing system like this is usually used in text message to show that the speaker means the word. When the word is not applying repeated letter, it could be refer to conventional English "her".

To define on what that word really is, the writer sees the word before heeer. There is a preposition "over", written before heeer. In conventional English, a preposition "over" can form an adverbial phrase to give a particular position. Since there are only two subjects ("I" and "you"), the writer concludes that heeer is heer with repeated letter and derived from an English word "here" instead of "her". This conclusion comes up because in conventional English, "here" is pronounced /hıә/. Since letter e in English is pronounced in various sounds $([\varepsilon]$ as in "elegant", $[i]$ as in "evil", or [I] as in "kid"), the diphthong of that word is be assumed by LOLcat users as double e. Hence, this pronunciation then is used to rewrite the word from "here" into heer. 
Therefore, if the words are rewritten using conventional English words, the sentence will be "I is way over here". According to the purpose of that utterance, the sentence is a declarative sentence because it is functioned as information towards the hearer. Syntactically, as a declarative sentence, the subject "I" has a verb "is" which is different with conventional English sentence. To express the simple present form, the verb for "I" is "am" (Azar, 2006: 6). However, the pronoun "I", which is functioned as a subject, has an iz as its verb which is similar with "is".

By modifying its auxiliary verb, LOLcat users turn a conventional English sentence "I'm way over here", into Iz way over heer. Words "way over" is used to emphasis the considerable extent.

\section{Picture 2}

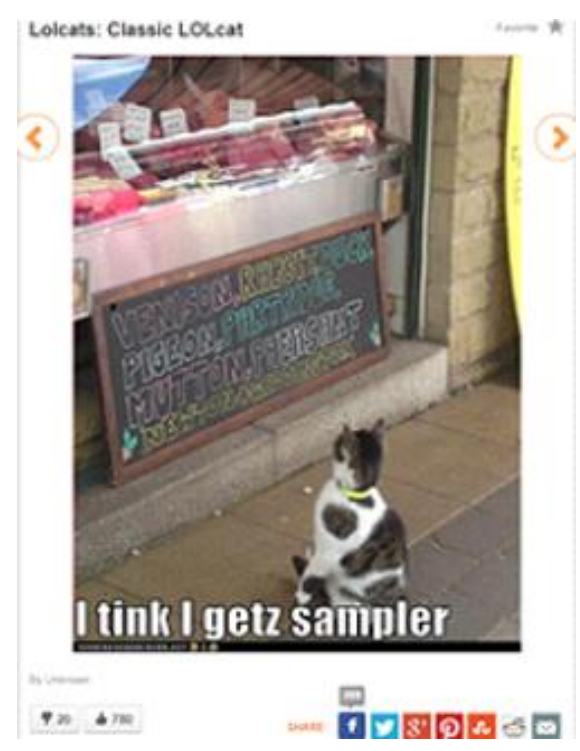

In picture 2 , there is only one sentence placed at the bottom of the picture. A Sentence I tink I getz sampler in that picture will be the datum.

As written there, tink is derived from an English word "think" which is modified through contraction process by deleting $h$ letter. Moreover, the getz word occurs as an effect of pronunciation implementation. Getz is borrowed from conventional English word "get" with a -z suffix.
"Get" as a verb, is sometimes has a suffix when it is used to describe the action of the third singular person in a simple present tense. The suffix for this word is -s so it becomes "gets". In phonology, "gets" is pronounced /gets/ because [ $\mathrm{t}$ ] is voiceless. However, the suffix -s is pronounced /z/ when it is after the voiced nonsibilant final segment (Fromkin, 2011: 229) such as comes /kımz/. On the contrary, in this datum, "gets" is rewritten into getz which, when it is being read, creates inner ear as if the [t] is voiced. The writer concludes that this modification occurs through influences of other voicednonsibilant-final-segment words. Sound [z] in other voiced-nonsibilant-final-segment words is then rewritten by LOLcat users in this meme.

Hence, the conventional English version of that sentence will be "I think I gets sampler" and formed in a declarative sentence. As a verb clause, the syntactic style in I gets sampler occurs since the verb "get" has -s suffix to explain "I". In conventional English, suffix -s is added in a verb if it describes the third singular person in a simple present tense (Azar, 2006: 53).

\section{Picture 3}

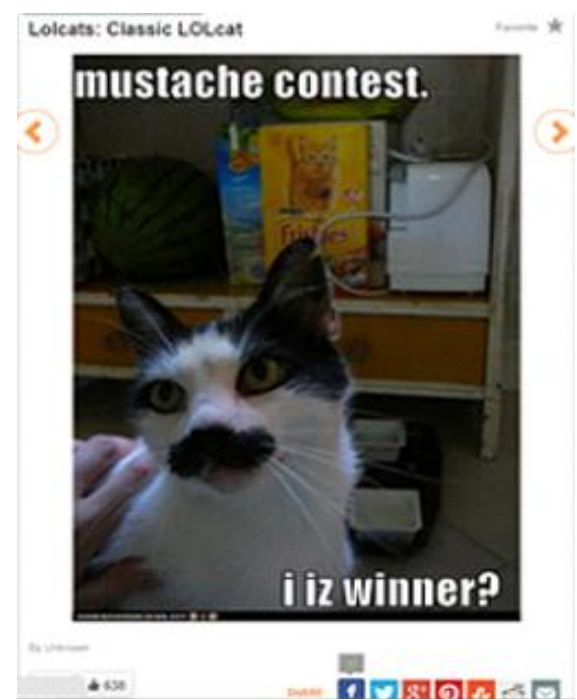

For picture 3, there are 2 sentences which are used as data in this study. The first phrase is written mustache contest and the second sentence I iz winner?

In the first phrase, it is written mustache contest. The word mustache derives from conventional English word "moustache" with 
a contraction feature by deleting the o letter. It is also an adjective of a noun "contest". In conventional English word, "contest" is a countable noun. Henceforth, it needs an article if it is a singular event. However, in this datum, the article is omitted, leaving the phrase only consists of "moustache" and "contest".

For the second phrase, the writer uses the result as shown in datum picture 1 . Sentence $I$ iz winner is similar to " $\mathrm{I}$ is winner?" where iz is a nonstandard spelling through implementing the pronunciation of an auxiliary verb "is". From this morphological finding, it is known that subject "I" has an "is" as its verb.

This form is different from conventional English grammar. In its grammar, "am" is a be form for pronoun "I" (Azar, 2006:7). Moreover, the article "the" is omitted. "The" in that sentence has a function to refer to a specific winner which is a moustache contest. Therefore, according to conventional English grammar, article "the" in that sentence is important.

As an interrogative yes/no question, the question in the meme is formed into a sentence. According to conventional English grammar, a yes/no question has a be form which comes before a subject as in a sentence "Am I doing this right?" (Azar, 2006: 24). However, in this datum from icanhas.cheezburger.com, "be" in the question comes after the subject.

While in conventional English grammar, people will write "am I the winner?", in icanhas.cheezburger.com, the sentence is modified into I iz winner?.

Therefore, for the first phrase, while in conventional English people will write "a moustache contest", LOLcat users will write mustache contest. This first phrase is important in this datum because it gives the theme of this picture. As seen in the picture that there is a white cat with black fur right above its mouth, people will simply refer it as a moustache. However, with the caption in the first phrase, readers know that the theme in this picture is not about a moustache but a contest. Without this first phrase, readers will now understand the meaning of the second phrase: it will remain unknown what kind of game the cat joins so that it becomes the winner.

\section{Picture 4}

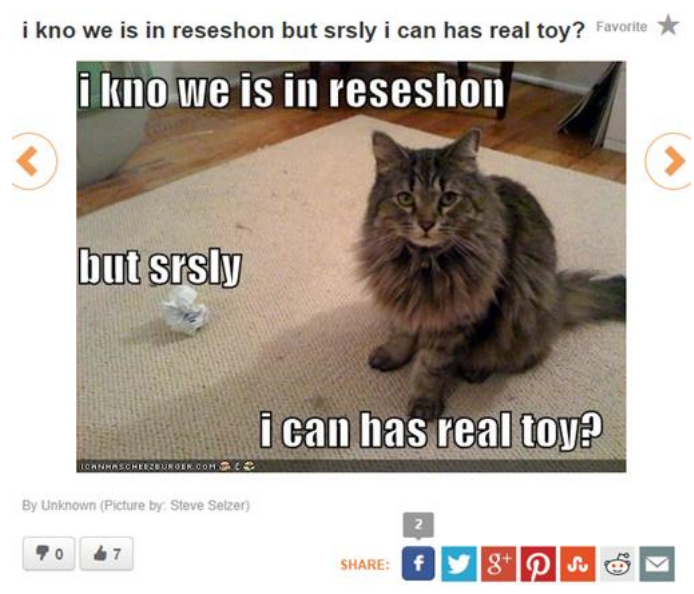

In this picture, the sentence is divided into 3 parts: top, middle, and bottom sentences. The analysis focuses on the top and the bottom sentences.

For the top sentence, it is written there, $I$ kno we is in reseshon. The readers' inner ear will be "I know we is in recession". In sense of morphology, the sentence applies clippings for deleting the letter $\mathrm{w}$ in "know" so it is written as kno.

Beside clippings, the sentence also applies a nonstandard spelling. It occurs in the word reseshon since it is created through an influence from other similar words. In English phonology, it is known that words which have palatal fricative sounds such as "shogun"/'Jəugun/, "sheep" / /iip/, or "fish" $/ \mathrm{fr} /$. Many "sh" letters in words are pronounced as []]. In "recession", however, although the word does not use "sh" letters, its English pronunciation is /ri'sef(ə)n/ which conveys the [J]. Users then rewrite letters sh from other words because those letters share the same sound as "recession". It is different from datum picture 3 where users implement the sound /iz/ into iz.

According to the morphological analysis, the conventional English words for that sentence are "I know we is in recession" and it expresses a declarative sentence. In 
syntactic level, the top sentence shows differences. "Is" is used rather than "are" as an auxiliary verb of "we". To indicate the present tense in conventional English grammar, "we" has an "are" as its auxiliary verb (Azar: 2006: 92). Although "is" is not written iz as in previous data (picture 1 and 3 ), how those words connect to each other are still different from conventional English sentence.

Moreover, there are two possibilities in that sentence because on the word "recession" does not have article or suffix. In conventional English, that word is a countable noun. Therefore, if "recession" in that sentence is singular, it should have an article "a" before the word. However, if the word "recession" is plural, it should have a suffix -s after that word.

While in conventional English people will say "I know we are in a recession" or "I know we are in recessions", LOLCat users will write it into I kno we is in reseshon.

For the bottom sentence, a question is written I can has real toy? This question form is morphologically correct. However, in term of syntax, the question is formed into a sentence as shown before in picture 3 . According to conventional English question form, a modal such as "can" appears before a subject (Azar, 2006: 357). On the contrary, in the text above, the modal appears after the subject "I".

Another difference appears in the verb of the text. "Has" is written instead of "have". According to conventional English, the auxiliary verb for a first person singular noun is "have".

As shown in several previous data, there is a possibility that an article is omitted. "Toy" as a countable noun should have an article to show its singularity. However, in the text, there is no article to show singularity or a $-\mathrm{s}$ suffix to show plurality.

Based on analysis above, the writer concludes that users of LOLcat meme write $I$ can has real toy? rather than "can I have a real toy?".

\section{Picture 5}

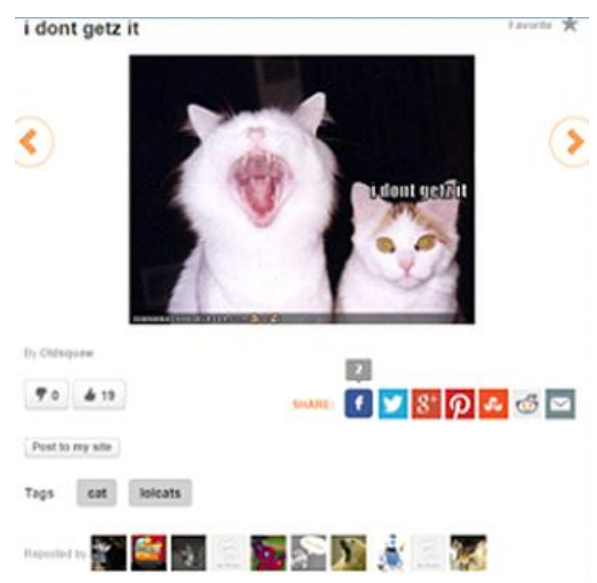

There is only one sentence in this meme which is I dont getz it. The word getz in that sentence conveys the same implementation of pronunciation as occurs in datum picture 2. The word getz comes from an English word "gets". "Gets" consists of a morpheme "get" and is followed by -s suffix. Its pronunciation is /gets/ because [ $t$ ] is voiceless. However, as an influence of other voiced-nonsibilant-finalsegment words such as "comes" /kımz/, getz is written rather than "gets" because LOLcat users rewrite the sound ([z]) into the written word as a feature of nonstandard spelling.

From this morphological analysis, it is known that I dont getz it is similar to "I don't gets it". As a declarative sentence, the verb is different from conventional English in term of syntax because a first singular person does not have an - s suffix in its verb. Since the verb "get" has a $-z$ suffix which is similar to $-s$ suffix, according to conventional English grammar, getz should not be added with a subject "I".

\section{Picture 6}

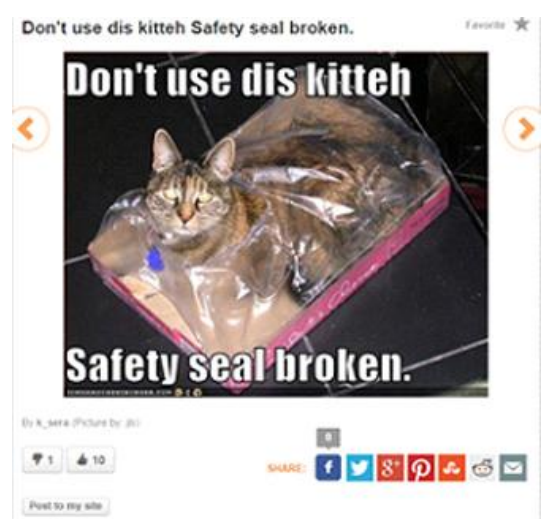


In this picture, the datum used is the sentence at the bottom of the picture. The sentence on the top is syntactically correct. As written there, don't use dis kitteh is an imperative sentence. According to lolcatbible.com, dis kitteh is similar to conventional English words "this kitty" which refers to the cat in the picture (lolcatbible.com, 18 Dec 2011: 8 June 2015). The occurrence of "don't" indicates the command not to use the kitty in the picture. Since the sentence is syntactically correct, it is excluded from the data.

The second sentence needs a syntactic analysis without any morphological analysis. That sentence shows an auxiliary omission "is". As a declarative sentence, there is something missing in the sentence. By looking at the past participle word "broken", it is known that the sentence is formed into a passive sentence. According to conventional English sentence, a passive form has an auxiliary verb before the verb as in "is gone" or "was burnt". Therefore, for the verb "broken", there must be an auxiliary "is" before it. However, in the datum above, the auxiliary verb is omitted. The omission also occurs in an article "the". That article is important to show a specific safety seal and not another safety seal.

As a conclusion, LOLcat users will write safety seal broken while in conventional English syntax, people will write "the safety seal is broken".

\section{Picture 7}

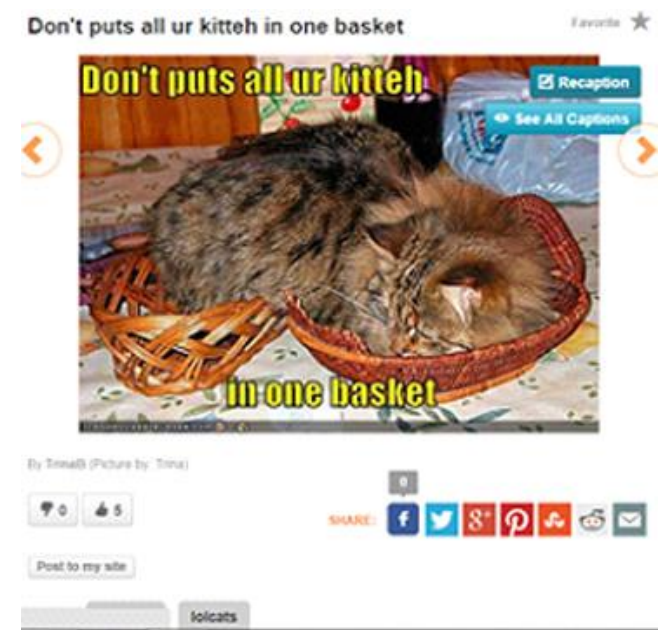

Although the sentences are written into two parts, they are actually a single complete sentence because the bottom part explains the top part. It is written don't puts all ur kitteh in one basket.

Morphologically, that sentence uses logogram for ur which represents "your" since $u$ /ju:/ has similar pronunciation to "you" /ju:/. As the result, "your" is changed into ur. Moreover, it also applies a nonstandard-spelling feature in kitteh which synonymous with "kitty" (lolcatbible.com, 18 Dec 2011: 1 December 2014)

Unlike other data which has a verb with a $-z$ ending (datum picture 2 and picture 6 ), the imperative sentence in this picture has a s suffix in the verb puts. Henceforth, this sentence differs from conventional English sentence since the subject ("you"), which verb does not need a - s suffix.

\section{Picture 8}

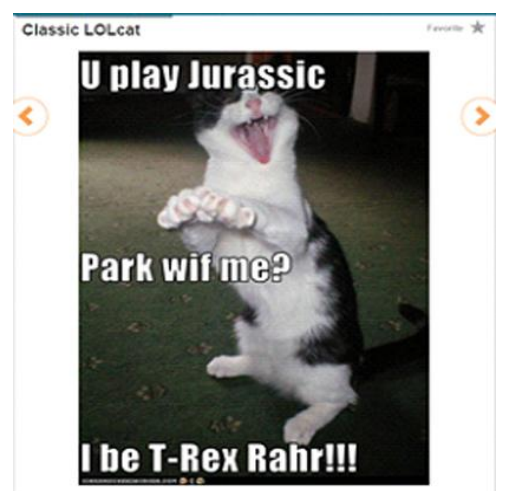

Those three lines of phrases consist of two sentences because the second line follows the first line. Hence, those two sentences are $U$ play Jurassic Park wif me? And I be T-Rex Rahr!!!

For the first sentence, it applies logogram and non-standard spelling. The logogram occurs in a word $u$ which represents "you". Both of those words shares similar pronunciation (/ju:/). Instead of using "you", users write it as $u$.

The non-standard spelling occurs in a word wif. The writer concludes that this writing comes up as an assimilation process in phonology. According to Victoria Fromkin, assimilation is "phonological process that 
changes feature values of segments to make them more similar". (Fromkin 2011: 571)

Syntactically, $u$ in that sentence functions as an agent, with play as a transitive verb. The word Jurassic park is a theme while $m e$ is a beneficiary. Henceforth, wif derives from a conventional English preposition "with" which ending -th is replaced with $-f$. This replacement is affected by the following voiced bilabial nasal [m] in the following word. The conventional English words "with me" has voiceless dental fricative $[\theta]$ in "with" is changed into voiceless labiodental fricative [f] because [f] is closer and easier to pronounce before pronouncing voiced bilabial nasal [m] in "me". This effect is what then LOLcat users reuse in the sentence.

Based on the analysis, the English word for the sentence is "you play Jurassic Park with me?". In a syntactic context, the sentence only consists of basic information about who, what, and with whom. Links between that information does not occur in the sentence. These absences affect an unknown tense. The sentence could be a present continuous tense or simple future tense. If it is a present continuous sentence, the deletion occurs in the auxiliary verb "are" and suffix -ing which make the sentence becomes "are you playing Jurassic Park with me?". However, if it is a simple future tense, modal "will" is omitted. When a modal "will" is added, the sentence becomes "will you play Jurassic Park with me?". This double interpretation affects the following sentence.

As seen that the sentence at the bottom is I be T-Rex Rahr!!! The word rahr is an onomatopoeia or a word in which the pronunciation resembles the sound. According to urbandictionary.com, rahr is onomatopoeia to represent a roaring sound (urbandictionary.com/define.php?term=Rahr , 23 March 2015). This onomatopoeia is used to represent a sound of a big wild animal. Since onomatopoeia is not a focus of this study, the part is going to be analyzed is $I$ be T-Rex.

The ambiguous meaning of the previous sentence affects the interpretation toward this sentence. If the previous sentence is in a present continuous tense, the sentence would be "I am a T-rex". However, this sentence would be "I will be a T-rex" if the previous sentence is in a simple future tense.

Based on syntactic analysis from data picture 1 until picture 8 , the writer concludes that most pictures have two lines of caption, although some of them have one line or more than two lines. The language in LOLcat uses omission, modification, and movement in its message delivered. The omission occurs by deleting subject (picture 1), auxiliary verb (picture 1, 6, and 8), article (picture 1, 3, 4, and 6), and modal (picture 8). In modification, LOLcat users change "am" into "is" (picture 1 and 3), "are" into "is" (picture 4), "have" into "has" (picture 4), "get" into "gets" (picture 2 and 5), and "put" into "puts" (picture 7). At last, the movement occurs by putting modals in front of the subject in a yes/no interrogative so a question form changes into a statement. All data results are put in the table below.

\begin{tabular}{|c|c|c|c|c|}
\hline NO. & DATA & OMISSION & MODIFICATION & MOVEMENT \\
\hline 1. & Picture 1 & $\begin{array}{l}\text { - "Do" as an auxiliary verb } \\
\text { - "1" as a subject } \\
\text { - "Am" as an auxiliary verb } \\
\text { - "The" as an article }\end{array}$ & - Change "am" into "is" & - \\
\hline 2. & Picture 2 & - - & - Change "get" into "gets" & - \\
\hline 3. & Picture 3 & $\begin{array}{l}\text { - "A" as an article } \\
\text { - "The" as an article }\end{array}$ & - Change "am" into "is" & $\begin{array}{l}\text { - Auxiliary verb "is" } \\
\text { comes after the } \\
\text { subject to express } \\
\text { yes/no interrogative }\end{array}$ \\
\hline 4. & Picture 4 & $\begin{array}{l}\text { " } A \text { " as an article is omitted if } \\
\text { the noun is singular }\end{array}$ & - Change "are" into "is" & $\begin{array}{l}\text { - Modal "can" comes } \\
\text { after the subject to }\end{array}$ \\
\hline
\end{tabular}


Vol. 16 №. 1 - April 2016

\begin{tabular}{|c|c|c|c|c|}
\hline & & $\begin{array}{l}\text { - Suffix }-s \text { is omitted if the } \\
\text { noun is plural }\end{array}$ & - Change "have" into "has" & $\begin{array}{ll}\text { express } & \text { yes/no } \\
\text { interrogative } & \end{array}$ \\
\hline 5. & Picture 5 & - - & - Change "get" into "gets" & - \\
\hline 6. & Picture 6 & $\begin{array}{l}\text { - "Is" as an auxiliary verb } \\
\text { - "The" as an article }\end{array}$ & I & - \\
\hline 7. & Picture 7 & - - & - Change "put" into "puts" & - \\
\hline 8. & Picture 8 & $\begin{array}{l}\text { - If it is a simple present } \\
\text { continuous sentence: "Are" } \\
\text { as an auxiliary verb and } \\
\text { suffix -ing. } \\
\text { - If it is a simple future } \\
\text { sentence: "Will" as a modal. }\end{array}$ & - "Be" is modified & - \\
\hline
\end{tabular}

By omitting those parts of speech, sometimes the language does not have any tenses as in picture 8. The most important part in every sentence in LOLcat is the message or the head of the sentence. It is proven since the main subject and main verb are written in conventional English.

As appearing in all data, no sentences are typed on the face of the cat's picture. They are typed in the top and/or the bottom of the whole picture. The picture is not covered because it gives a big role in delivering the message. The writer finds that in order to catch the message, readers have to correlate the words with the picture. For an example in a picture 3 where there is a picture of a cat which has black fur right on its mouth. In order to give the humorous situation, the word there (mustache) tries to inform that the fur is a moustache. Henceforth, sentences in LOLcat meme are meant to describe the picture.

Since LOLcat only has limited space, sentences written there are usually consist of one sentence (picture 2 and picture 5),

two sentences (picture 1, picture 3 , picture 6 , picture 7 , and picture 8 ). There is only one picture (picture 4) which has three sentences.

Based on this nature, the writer concludes that it is logical that the unconventional English is created because the limited space. However, as an internet product, LOLcat meme is not the only meme. As known before that internet meme nowadays are 2,116 (www.knowyourmeme .com/memes: May 10, 2015), LOLcat meme has free word variations while other memes have patterned sentences. According to the previous analysis, topic which is talking in LOLcat meme varies from declarative, interrogative, and imperative. Therefore, concluding that the conventional English appears as a result of limited space is too shallow.

\section{The Effect of Unconventional English Syntax towards Virality}

From communication perspective, the writer sees that this language phenomenon does not violate the meaning of transferring the message. Although many words are modified, the core idea of a sentence is not changed. As appear in the examples above, words like "contest", "winner", or "toy" are quite enough for readers to get the idea of the picture. The modifications, however, create a simple yet free form of using the language itself.

Regarding the fact that internet is a place where people from all around the world meet and talk, LOLcat meme provides each user to transfer any messages in a simple grammar. Its easy structure maintains fidelity of LOLcat meme since such structure only occur in this meme. It also has to be underlined that finally, users from France can communicate with an American using English without difficulties to memorize that "I" should have an "am" as its auxiliary verb. Since more people can apply the idea of this meme, more meme can be promoted in the website.

Therefore, simplicity and freedom are identities of LOLcat meme although it is very 
possible that other internet memes with the same feature will emerge. Those modifications, simplifying, and moving make LOLcat meme unique, attractive, and easy to be memorized so that more internet users can use LOLcat meme.

\section{Conclusion}

Existing among many other internet memes, LOLcat meme has features the other memes does not have; freedom and simplicity. Although this meme first appeared in 2005 , today it is the only meme that has a website and even the Bible version. LOLcat meme is the only meme in the internet in which users can use it for communication because users can use any words to express any ideas without difficulties to memorize the English grammar.

In using the language, LOLcat meme usually manipulate words through clipping, logogram, contraction, and nonstandard spelling. In nonstandard spelling, users even transform the sound into word; make it as how the word is sounded. Some unconventional words are widely used as they appear in several memes such as $i z$ or "is" and haz or "has".

Syntactically, there are three variations that is applied in LOLcat meme; omission, modification, and movement. Omission occurs by deleting subject, auxiliary verb, article, and modal. In modification, LOLcat users tend to use iz or "is" and haz or "has" rather than "am", "are", or "have". Meanwhile, movement usually occurs in a yes/no interrogative question where "has" and "can" precede the subject.

Those features make LOLcat meme survive among other internet memes. They maintain the fidelity, fecundity, and longevity. Although some messages could be ambiguous, the virality of LOLcat meme proves that such features can be accepted by internet users from all around the world.

\section{References}

Blackmore, Susan. The Meme Machine. Oxford: Oxford University Press, 1999.

Chen, Carl. "The Creation and Meaning of Internet Memes in 4chan: Popular Internet Culture in the Age of Online Digital Reproduction". Habitus. Vol. 3 no. 1 (2012): pp. 6-19, 2012.

Crystal, David. Language and the Internet. Cambridge: Cambridge University Press, 2001.

Crystal, David. Txtng: The Gr8 Db8. Oxford: Oxford University Press, 2008.

Dash, Anil. "Cats Can Has Grammar". A Blog About Making Culture. n.p.. April 23, 2007. (www.dashes.com/anil/2007/ 04/cats-can-has-gr.html). December 10, 2013.

Dawkins, Richard. The Selfish Gene. Cambridge: Cambridge University Press, 2006.

Fromkin, Victoria et al. An Introduction to Language. Canada: Wadsworth Cengage Learning, 2011.

Katamba, Francis. Morphology. New York: St. Martin's Press, Inc., 1993.

Knobel, Michele \& Colin Lankshear. "Online Memes, Affinities, and Cultural Production". A New Literacies Sampler. Vol. 29 no. 9 (2007): pp. 199-228.

Langton, Jerry. Funny how 'stupid' site is addictive. Thestar.com. np.. September 22 2007. www.thestar.com. August 21 2014.

O'Grady, William and John Archibald. Contemporary Linguistics: an Introduction. New York: Bedforth/St. Martin, 2010. 
Pastor-Satorras, Romualdo and Alessandro Vespignani. Evolution and Structure of the Internet: A Statistical Physics Approach. Cambridge: Cambridge University Press. 2004.

Preston, Paschal. Reshaping Communication. London: SAGE Publications. 2001.

Ritt, Nikolaus. Selfish Sounds and Linguistic Evolution. Cambridge: Cambridge University Press. 2004.

Rosen, Rebecca J. Are LOLCats Making Us Smart?. Atlantic.com. Atlantic Media. May 8 2012. www.atlantic.com. January 16 2014. 